\title{
Shrinkage modeling, drying kinetics and quality assessment of carrot cubes dried in a two stage spouted bed drying process
}

\author{
Cárdenas-Bailón $\mathrm{F}^{1}$, Pérez-Vázquez $\mathrm{C}^{1}$, Osorio-Revilla $\mathrm{G}^{1 *}$ and Gallardo-Velázquez $\mathbf{T}^{2}$ \\ ${ }^{1}$ Departamento de Ingeniería Bioquímica, ${ }^{2}$ Departamento de Biofísica. Escuela Nacional de Ciencias Biológicas Instituto Politécnico Nacional \\ México. Prolongación de Carpio y Plan de Ayala S/N, Del. Miguel Hidalgo, C.P. 11340 México, D.F.
}

\section{A B S T R A C T}

\begin{abstract}
A relatively easy to apply mathematical model based on the second Fick's law inserting a correction factor $\alpha$ to describe drying kinetics of unblanched carrot cubes in a two stage drying process considering shrinkage, using a semipilot spout bed dryer for the first stage and a lab scale spout fluidized bed dryer for the second stage was successfully developed. Drying of the carrot cubes was done at three drying temperatures 60,70 and $80^{\circ} \mathrm{C}$. It was possible to keep air velocity constant in each drying stage $1.65 \mathrm{~m} / \mathrm{s}$ at the first stage and $0.68 \mathrm{~m} / \mathrm{s}$ and $1.35 \mathrm{~m} / \mathrm{s}$ in the annulus and spout respectively in the second stage. Effective moisture coefficients obtained 0.821 to $1.02 \times 10-9 \mathrm{~m}^{2} / \mathrm{s}$ for the first drying stage and 0.262 to $0.481 \times 10-9 \mathrm{~m}^{2} / \mathrm{s}$ for the second drying stage were according to the published data for carrots in this kind of dryer considering shrinkage. The model fitted accurately the experimental drying with SEE of 0.122 to 0.210 when shrinkage was considered and $\alpha$ correction factor was inserted compared to SEE of 1.002 to 1.263 when shrinkage was neglected. Also residual analysis of models confirmed the adequacy of the model to predict drying kinetics. Quality parameters obtained $\beta$-Carotene retention $(80 \pm 5.4 \%)$, peroxidase residual activity (30-35\%), pectin methyl esterase residual activity $(83-95 \%)$ and rehydration ratio $(4.5-5.3$ water absorbed/kg dried solids) resulted similar to the ones reported in the literature and except for $\beta$-Carotene retention they all showed dependence with drying temperature.
\end{abstract}

Keywords: Carrot; Dehydration; Spout fluidized bed dryer; Shrinkage

\section{INTRODUCTION}

Dehydration of vegetables and fruits is a process of paramount importance in food technology. Simultaneous heat and mass transfer from the outer face and into the foodstuff, hot air hydrodynamics, movement of driblets in the dryer, different mechanisms of moisture transport within the foodstuff and size depletion, are some issues associated with food dehydration (Hatamipour and Mowla, 2002). Probably, the most relevant physical change that food suffers during the drying process is volume depletion. Temperature increase and loss of moisture content cause a high stress in the cellular building of the food products, leading to change in form and a depletion of the particles volume (Arevalo-Pinedo et al., 2010).

On the other hand, so as to simulate and make more effective the drying process, it is essential to know the effective moisture diffusivity coefficient of the product to be dried (Hassini et al.,
2007). The estimation of the effective moisture diffusivity coefficients for biological products is usually carried out using experimental drying data and applying the second Fick's law for different geometries of the product. In the past, this estimation was done without considering shrinkage effect. Several researchers have tried to take into account shrinkage phenomena during estimation of effective moisture diffusivity coefficients and mathematical modeling of dehydration kinetics; among these, Mulet, (1994) used mathematical linear correlations to associate shrinkage with humidity content. He found that shrinkage effect cannot be disregarded during estimation of trustworthy values of effective diffusion coefficients. Sjölmon and Gekas, (1995) tried to evaluate shrinkage of apples slices dried in a convection oven by relating the starting bulk mass of the sample with the bulk mass at any time including an exponential correction factor, without much success. Mc Minn and Magee, (1997) reported a mathematical linear model correlating shrinkage with moisture content and air temperature during dehydration

\footnotetext{
*Corresponding author:

Osorio-Revilla G, Departamento de Ingeniería Bioquímica, Prolongación de Carpio y Plan de Ayala S/N, Del. Miguel Hidalgo, C.P. 11340

México, D.F. Phone: (55) 57296000. Ext.: 62305 \& 62454. E-mail: osorgi@gmail.com
}

Received: 21 January 2019; $\quad$ Accepted: 18 July 2019 
of cylindrical potato samples in a tunnel dryer. McLaughlin and Magee, (1998) predicted potato spheres dehydration in a fluidized bed dryer successfully by using the Fick's second law incorporating a Fourier number accounting for shrinkage. Hatamipour and Mowla, (2002) were able to correlate carrots volume depletion during dehydration in a fluidized bed dryer with humidity content of the sample.

More recently, Zielinska and Markowsky, (2007) correlated the shrinkage data with moisture content by a linear equation during carrot cubes dehydration in a spouted bed dryer. They found that coefficients of the linear equation are highly influenced by blanching, and effective moisture coefficients resulted lower when shrinkage was considered than when no shrinkage was taken into account. Białobrzewski et al., (2008) worked out a mathematical model to depict heat and mass transfer during carrot cubes dehydration in a spout fluidized bed dryer using Lagrange-Eulerian formulation, in which solid particles were considered as a discrete phase. The mathematical model considered the heterogeneous volume depletion of the carrot cubes. However the model failed to predict drying kinetics accurately since errors of more than $50 \%$ were reported and model requires numerical solving of three linked equations making it unpractical for a direct application. Arevalo-Pinedo et al., (2010) evaluated effective moisture diffusion coefficients considering both shrinkage and no shrinkage of carrot slices in a vacuum dryer using Fick's second law for a slab and they found that the effective moisture diffusion coefficients were higher when no shrinkage was considered. Also, Zielinska and Markowsky (2010) developed two models based on Fick's second law to predict dehydration kinetics of carrot cubes in a spout bed dryer and found that volume depletion should be considered in order to obtain trustworthy values of effective moisture diffusivity in carrots. These authors found that if volume depletion is not considered during mathematical modeling of dehydration kinetics, then the effective moisture diffusivity in carrots can be miscalculated at the starting and final dehydration stage. Aversa et al., (2011) evaluated shrinkage during drying of eggplant disks in a moisture analyzer finding a non-linear dependence of food volume with moisture content. Brasiello et al., (2013) developed two mathematical models considering volume depletion effect describing eggplant dehydration. The models are both modified diffusion equations that consider different changes of eggplant slice structure during drying. In the foremost model a diffusion coefficient variable with the humidity content is considered whereas in the second model an unreal convective term was introduced. Both models were capable to describe the analyzed dehydration processes. Aprajeeta et al., (2015) studied volume depletion and porosity changes along with coexisting heat and mass transport during potato slices dehydration in a convective cabinet dryer. They studied the influence of volume depletion and porosity on heat and mass transfer and modeled the data without much success. Brasiello et al., (2017) analyzed the evolution of moisture content profiles inside cylindrical samples of eggplant during dehydration using magnetic resonance imaging taking into account shrinkage effects.

As can be seen from the above reports, considering shrinkage effect is essential to build suitable mathematical models to depict dehydration kinetics of food products. Also, models should be practical and relatively easy to apply and should provide accurate prediction of drying kinetics. Based on this, the aim of this work was to build a mathematical model with base on Fick's second law, both considering shrinkage effect and neglecting it, to predict drying kinetics of carrot cubes in a two stage dehydration process using a semipilot spouted bed dryer in the first step and a lab scale spout-fluidized bed dryer in the second stage, as well as to evaluate the effect of drying parameters on product quality ( $\beta$-carotene content, rehydration ratio and both pectin methyl esterase PME and peroxidase POD residual activity as thermal degradation indicators). The methodology developed in the present work can be applied to any food product.

\section{MATERIALS}

\section{Material}

Carrots (Daucus carota) used in this research were Nantes cultivar. They were acquired from a local market and kept under refrigeration at $3 \pm 1^{\circ} \mathrm{C}$ for maximum 2 weeks before drying. Carrots were washed, hand-peeled and the crown was peeled off. After that, the ends were cut and finally carrots were slashed into cubes of about $8 \mathrm{~mm}$ per side. In order to homogenize cubes size, they were sieved through a $9 \mathrm{~mm}$ sieve and only those cubes remaining over the sieve were used.

\section{Equipment}

It has been reported (Zielinska and Markowsky, 2007) that batch dehydration of carrot cubes in a spouted bed dryer requires a continuous reduction of air velocity as drying progresses due to considerable shrinkage of the product. For this reason, in this work drying of carrots was done in two stages so that air velocity could remain constant in each drying stage. Drying of carrots cubes was performed using a conventional semipilot spouted bed dryer for the first stage and a lab scale spout-fluid bed dryer with draft tube for the second stage. The setup of the conventional semipilot spouted bed dryer can be seen in Fig. 1a. The drying chamber in the conventional semipilot spouted bed dryer consisted of a Perpex ${ }^{\mathcal{O}}$ cylinder $0.6 \mathrm{~m}$ height, $0.25 \mathrm{~m}$ inner diameter with a wall thickness of $6 \mathrm{~mm}$ and it was mounted on a stainless steel conical section with $60^{\circ}$ internal 
angle. Above the drying chamber there was a $4 \mathrm{~mm}$ stainless steel mesh in order to avoid the material to pop out from the drying chamber. The mesh had a circular hole where a stainless steel feeding chute was inserted. The required air for the spout was supplied by a high pressure turbo blower. The heating system consisted on a LP gas burner controlled by a needle valve and temperatures were evaluated using a K-type thermocouple. The air velocity was measured through orifice meters with water U-tube manometer. The setup of the lab scale spout-fluid bed dryer with draft tube is illustrated in Fig. 1b. The drying chamber consisted of a Perpex ${ }^{\odot}$ cylinder $0.7 \mathrm{~m}$ height, $0.142 \mathrm{~m}$ inner diameter with a wall thickness of $6 \mathrm{~mm}$ mounted on a conical stainless steel base $\left(0.25 \mathrm{~m}\right.$ height, $60^{\circ}$ internal angle) with $1 \mathrm{~mm}$ diameter holes all over the surface to distribute the air through the annular region. The air for the spout and annulus, was provided and regulated by two independent high pressure turbo blowers as can be seen in Fig. 1b. The heating system consisted on electric resistances regulated by a proportionalintegral-derivative controller; temperatures were monitored utilizing K-type thermocouples. Air velocity was measured in both, the annular region and the spout by the corresponding orifice meters and water U-tube manometer.

\section{Methods}

\section{Drying conditions}

For the drying runs in the first stage in the conventional semipilot spouted bed dryer, three different air inlet temperatures were used $\left(60,70\right.$ and $\left.80^{\circ} \mathrm{C}\right)$. Once the drier

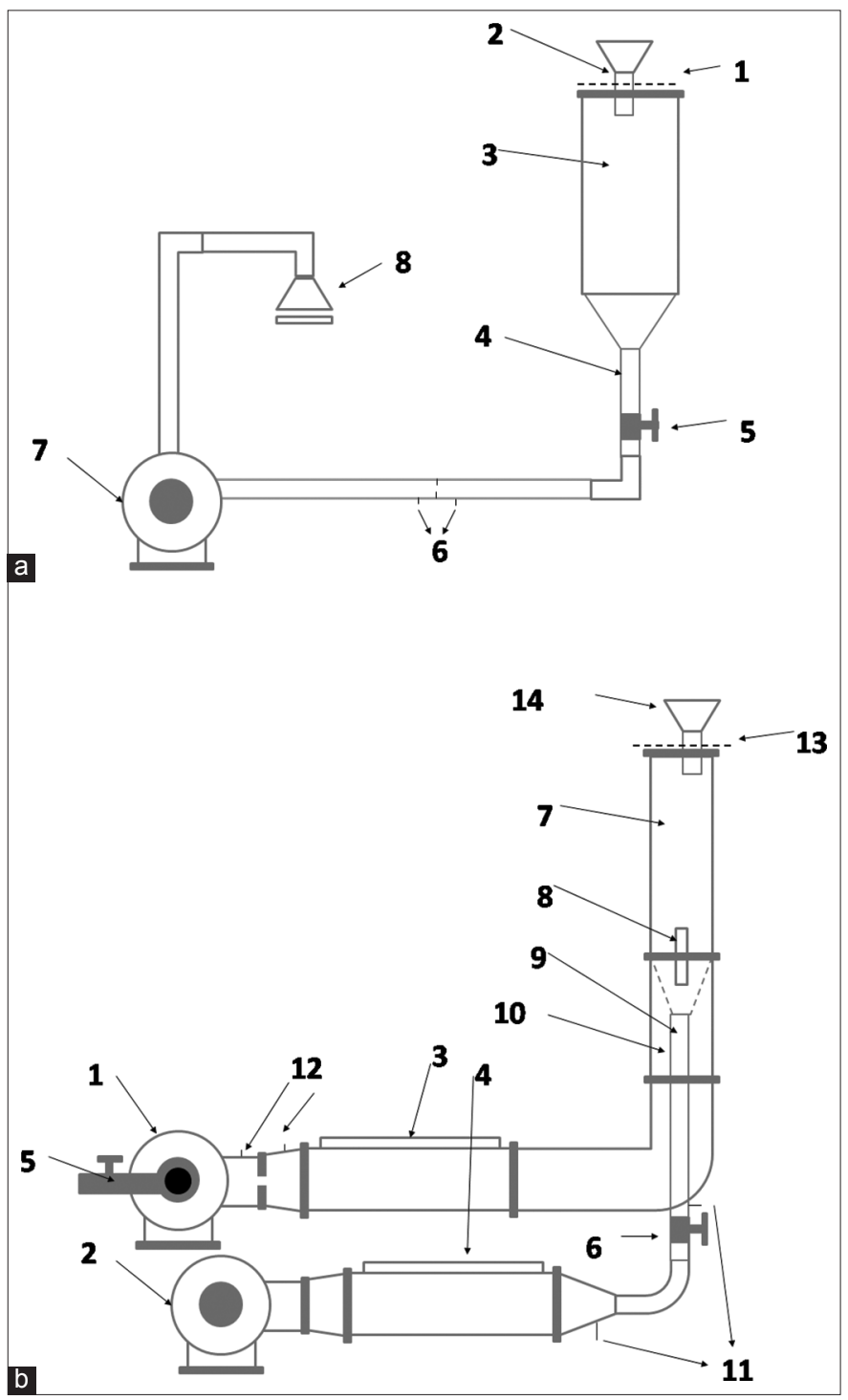

Fig 1. Schematic diagram of experimental equipment a: (conventional semi pilot spouted bed dryer) 1 mesh to retain product; 2 feeding chute; 3 drying chamber; 4 inlet drying air; 5 air flow control valve; 6 orifice flow meter to evaluate air velocity; 7 centrifugal turbo blower; 8 gas burner. b: (Lab scale spout fluidized bed dryer with draft tube) 1, 2 centrifugal turbo blowers; 3, 4 heating system; 5,6 air flow control valves; 7, drying chamber; 8 , draft tube; 9 , inlet spout air; 10 , additional annular air; 11, 12, orifice flow meters to evaluate air velocity; 13 mesh to retain product particles.; 14 feeding chutes. 
reached the desired temperature, $1.98 \mathrm{~kg}$ of unblanched carrot cubes equivalent to a bed depth equal to the height of the conical section of the dryer $(\mathrm{H} / \mathrm{D}=1)$ were added through the feeding chute. Initial moisture content was around 8 to $8.5 \mathrm{~kg}$ water $/ \mathrm{kg}$ dried solids. The superficial air velocity was maintained constant at $1.65 \mathrm{~m} / \mathrm{s}$. Finally, the carrot cubes were dehydrated in the first stage until they reached a humidity content of about $2.5 \mathrm{~kg}$ water $/ \mathrm{kg}$ dried solids.

For the second drying stage, $650 \mathrm{~g}$ of carrot cubes (obtained from the first stage of drying) equivalent to a $\mathrm{H} / \mathrm{D}$ ratio of 1 (bed depth/drying chamber diameter) were added to the lab scale fluidized bed drier through the feeding chute. The drying runs were carried out at the same drying temperatures used in the first stage of drying. The same air inlet temperature was used through the annulus and through the spout. The air velocities in the annulus and in the spout were kept constant throughout the drying run $(0.68 \mathrm{~m} / \mathrm{s}$ and $1.35 \mathrm{~m} / \mathrm{s}$ respectively). Carrot cubes were dehydrated in the second stage until a final humidity content of $0.1 \mathrm{~kg}$ of water $/ \mathrm{kg}$ of dried solids.

\section{Drying curve}

Dehydration curves of carrots in the conventional semipilot spouted bed dryer from the first stage, were obtained by taking a sample of 10 cubes from the drying chamber every $10 \mathrm{~min}$ during the first $50 \mathrm{~min}$ of drying. Humidity content of the samples was assessed in an oven Carlo Erba Unitherm (Val de Ruil, France) at $105^{\circ} \mathrm{C}$ until constant weight. In the second stage of drying also, samples of 10 cubes were removed every $10 \mathrm{~min}$ during the foremost hour of drying, every $20 \mathrm{~min}$ during the second hour of drying, every 30 min during the third hour and every $60 \mathrm{~min}$ during the subsequent hours. In order to compare the dehydration curves at different drying parameters, the dimensionless moisture content calculated as the proportionof humidity content dry basis $(X)$ at any time $\mathrm{t}$ with respect to the starting humidity content dry basis $\left(\mathrm{X}_{\mathrm{o}}\right)$, was plotted as a function of the drying time $\mathbf{t}$.

\section{Determination of sphere equivalent radius \\ Volume calculation}

The volume of the carrot cubes was measured at different drying times by introducing in vegetable oil a number of cubes in a glass graduated cylinder, measuring the displaced volume by the cubes and dividing it by the number of cubes. At the beginning of the drying the geometrical shape of the carrots was a cube, but as drying progresses this shape is lost and particles with irregular shape are obtained. For that reason, the volume of the particles was calculated as the volume of a sphere. So, the sphere equivalent radius $\left(\mathbf{r}_{\text {eq }}\right)$ of the particles at any time $\mathbf{t}$ can be expressed by equation 1 .

$$
r_{\mathrm{eq}}=\sqrt[3]{\frac{3 \mathrm{~V}}{4 \pi}}
$$

Where $\mathbf{V}$ is the dried cubes volume $\mathrm{m}^{3}$ at any time $\mathbf{t}$ and $\mathbf{r}_{\mathrm{eq}}$ is the radius of the equivalent sphere in $\mathrm{m}$ at any time $\mathbf{t}$.

\section{Effective moisture diffusivity coefficient calculation without considering shrinkage effect}

Since the volume of the particle changes with time, the mean logarithmic radius (LNR) between the undried cubes and the dried carrot cubes was used as shown in equation (2).

$$
L N R=\frac{r_{\text {eqo }}-r_{\text {eqf }}}{\ln \left(\frac{r_{\text {eqo }}}{r_{\text {eqf }}}\right)}
$$

Where $r_{\text {eqo }}$ is the sphere equivalent radius of undried carrot cubes and $r_{\text {eqf }}$ is the sphere equivalent radius of dried particles in $\mathrm{m}$.

The effective moisture diffusivity coefficient was estimated using Fick's second law (Crank, 1975) for a sphere taking into account only the first term of the series (equation 3).

$$
\Gamma=\left[\frac{X-X_{e}}{X_{o}-X_{e}}\right]=\left[\frac{6}{\pi^{2}}\right] e^{\left(-\frac{\pi^{2} D_{e f} t}{L^{2}}\right)}
$$

Where $\Gamma$ is the unaccomplished moisture, $\mathrm{X}$ is the humidity content on dry basis at any time $t, \mathrm{X}_{e}$ is the dry basis equilibrium humidity content of the carrot cubes, $\mathrm{X}_{\mathrm{o}}$ the dry basis starting humidity content of carrots, $\mathrm{D}_{\text {ef }}$ the effective diffusivity in $\mathrm{m}^{2} / \mathrm{s}$, and $\mathrm{t}$ the drying time in $\mathrm{s}$.

The $\ln \Gamma$ was plotted as a function of time and the effective diffusion coefficients were evaluated from the slopes using the LNR between the undried carrot cubes and the dried cubes.

\section{Effective moisture diffusivity coefficient calculation taking into account the shrinkage effect}

So as to consider the shrinkage effect during effective moisture diffusivity calculation, volume of the sample was measured as a function of the drying time $\mathbf{t}$. Shrinkage of carrot cubes during spout-fluidized drying was determined by Mulet, (1994) with the linear equation (4):

$$
\frac{\mathrm{V}}{\mathrm{V}_{\mathrm{o}}}=\mathrm{A} \frac{\mathrm{X}}{\mathrm{X}_{\mathrm{o}}}+\mathrm{B}
$$

Where $\mathrm{V}_{\mathrm{o}}$ is the initial volume of fresh carrot cubes in $\mathrm{m}^{3}$, $\mathrm{V}$ and $\mathrm{X}$ are the volume of the carrot cubes and humidity content on dry basis respectively at any time $t$. A and B are the constants obtained from plotting $\mathrm{V} / \mathrm{V}_{\mathrm{o}}$ as a function of $\mathrm{X} / \mathrm{X}_{\mathrm{o}}$. Shrinkage was considered during calculation of the 
characteristic dimension of a carrot cube $\left(\mathrm{r}_{\mathrm{eq}}\right)$ considering it as a sphere. Therefore changes of $r_{\text {eq }}$ as a function of time were calculated from equation (5) as follows:

$$
\frac{\mathrm{V}}{\mathrm{V}_{\mathrm{o}}}=\left(\frac{\mathrm{r}_{\mathrm{eq}}}{\mathrm{r}_{\mathrm{eqo}}}\right)^{3}=\mathrm{A} \frac{\mathrm{X}}{\mathrm{X}_{\mathrm{o}}}+\mathrm{B}
$$

Fick's second law for a sphere using only the first term of the series can also be written in the form of equation (6) (Krokida and Maroulis, 1997):

$\operatorname{Ln} \Gamma=\operatorname{Ln}\left[\frac{X-X_{e}}{X_{o}-X_{e}}\right]=\operatorname{Ln}\left[\frac{6}{\pi^{2}}\right]-\frac{\pi^{2} D_{e f} t}{r_{e q}^{2}}$

Combining equation (5) with equation (6) the result is equation (7)

$$
\begin{aligned}
& \operatorname{Ln} \Gamma=\operatorname{Ln}\left[\frac{\mathrm{X}-\mathrm{X}_{\mathrm{e}}}{\mathrm{X}_{\mathrm{o}}-\mathrm{X}_{\mathrm{e}}}\right]=\operatorname{Ln}\left[\frac{6}{\pi^{2}}\right]- \\
& \pi^{2} \mathrm{D}_{\text {ef }} \frac{\mathrm{t}}{\left[\mathrm{r}_{\text {eqo }}\left(\mathrm{A} \frac{\mathrm{X}}{\mathrm{X}_{\mathrm{o}}}+\mathrm{B}\right)^{1 / 3}\right]^{2}}
\end{aligned}
$$

So, by plotting the $\operatorname{Ln} \boldsymbol{\Gamma}$ as a function of $\mathbf{t} / \mathbf{r}_{\mathrm{eq}}{ }^{2}$ a linear plot in the form of equation (8) is obtained

$$
\operatorname{Ln} \Gamma=\mathrm{C}-\mathrm{m} \frac{\mathrm{t}}{\left[\mathrm{r}_{\mathrm{eq}}\right]^{2}}
$$

Where $\mathbf{m}$ is the slope $\left(\pi^{2} \mathrm{D}_{\mathrm{ef}}\right)$ of the linear curve in $\mathrm{m}^{2} / \mathrm{s}$ and $\mathrm{C}$ is the ordinate to the origin which is equal to $\mathrm{Ln}$ $\left(6 / \pi^{2}\right)$ for a spherical geometry. So the effective moisture coefficient can be obtained from the slope of the curve. In order to build an empirical mathematical model to depict the drying kinetics of the carrot cubes using Fick's second law for a sphere, an adjusting factor $(\alpha)$ was applied in $\mathbf{C}$ to take into account the deviation of the carrot cube particles from a sphere as shown in equation (9).

$$
\alpha=\frac{C}{\operatorname{Ln}\left[\frac{6}{\pi^{2}}\right]}
$$

Where $\alpha$ is a dimensionless adjusting factor to fit the experimental data to Fick's second law for a sphere. So the empiric model can be written as equation (10).

$$
\left.\left.\left[\frac{X-X_{e}}{X_{o}-X_{e}}\right]=\left[\frac{6}{\pi^{2}}\right]^{\alpha} e^{\left(\left[\mathrm{r}_{\text {eqo }}\left(A \frac{X}{X_{o}}+B\right)^{1 / 3}\right]^{2}\right.}\right]\right)
$$

\section{Mathematical validation of models with and without shrinkage effect}

In order to evaluate the accuracy of the models developed with respect to experimental data, the standard error of estimate (SEE) was evaluated using equation (11) (Montgomery, 2002):

$$
\mathrm{SEE}=\sqrt{\mathrm{MSE}}
$$

Where MSE, the mean square error, was assessed by using equation (12) (Montgomery, 2002):

$$
\operatorname{MSE}=\frac{1}{\mathrm{n}} \sum_{\mathrm{i}=1}^{\mathrm{n}}\left(\mathrm{y}_{\mathrm{it}}-\mathrm{y}_{\mathrm{ip}}\right)^{2}
$$

Where $\mathbf{n}$ is the number of values, $\mathbf{y}_{\mathbf{i t}}$ is the nth observed value and $\mathbf{y}_{\mathrm{ip}}$ is the nth predicted value.

Residuals $e_{i}$ were estimated using equation (13) (Montgomery, 2002)

$$
e_{i}=y_{i t}-y_{i p}
$$

Residuals were plotted against $y_{\text {it }}$ in order to evaluate the error and adequacy in the fit of the model to the $i_{\text {th }}$ observation $\mathrm{y}_{\mathrm{i}}$.

\section{$\beta$-carotene analysis}

$\beta$ carotene analysis was done as reported by Zheng-Wei et al., (2004). Complete description of the method has been described elsewhere (Cardenas-Bailon et al., 2017). Carotenoids was expressed as $\beta$-carotene content. Undried and dried samples were analyzed in duplicate for each drying run.

\section{Residual enzymatic activity} Extraction of enzymes in undried and dried samples Extraction of enzymes was done as described by CardenasBailon et al., (2017) and Morales-Blancas et al., (2002). Extracts were performed in triplicate.

\section{Evaluation of peroxidase (POD) residual activity}

POD residual activity was measured by keeping track of the change in absorbance at $460 \mathrm{~nm}$ upon oxidation of the substrate o-dianisidine catalyzed by the POD following the method reported by Castro et al., (2008). The activity was 
measured using the slope of the linear segment of the curve. One unit of POD activity was outlined as the increase in absorbance at $460 \mathrm{~nm}$ per minute per gram of dried solid. POD residual activity was expressed as the POD activity of the dried samples with respect to that of the fresh samples.

\section{Determination of pectin methyl esterase (PME) residual activity}

PME residual activity was evaluated by titration of free carboxylic acid groups released by PME during hydrolysis of a pectin solution at $\mathrm{pH} 7.5$ (Anthon et al., 2002; Nguyen et al., 2002; Stoforos et al., 2002). The volume of $\mathrm{NaOH}$ used $\left(\mathrm{V}_{\mathrm{NaOH}}\right)$ in titration was tracked as a function of time. Determinations were performed in triplicate.PME activity was obtained from the slope of the linear plot of the $\mathrm{NaOH}$ volume used in the titration as a function of time referred to the dried matter. PME residual activity was expressed as the PME activity of the dried samples with respect to that of the fresh samples.

\section{Rehydration ratio}

Rehydration ratio was carried out as described by Zielinska and Markowski, (2007) The rehydration kinetics was carried out within $60 \mathrm{~min}$ in two stages, at $90^{\circ} \mathrm{C}$ for $10 \mathrm{~min}$ (first stage) and at $60^{\circ} \mathrm{C}$ for $50 \mathrm{~min}$ (second stage). Mass of the samples was measured after removing the excess of water with tissue paper. Rehydration ratio was expressed as the water absorbed (g) divided by the dried sample weight (g).

\section{Statistical analysis}

The data were analyzed by ANOVA $(p<0.05)$ using the statistical software Minitab 16 (Minitab Inc. State College PA USA).

\section{RESULTS AND DISCUSSION}

\section{Drying kinetics}

Drying kinetics of the two stage drying process of carrot dices in the conventional semipilot spouted bed dryer and the lab scale spout fluidized bed dryer is showed in Fig. 2 for 80,70 and $60^{\circ} \mathrm{C}$. In the first stage of drying, carrot dices were dehydrated until a humidity content of $2.5 \mathrm{~kg}$ water $/ \mathrm{kg}$ dried solids was reached before going to the second drying stage in the lab scale spout fluidized bed dryer. As observed in Fig. 2, a constant drying period was not obtained.

\section{Effective moisture diffusivity coefficient calculation without considering shrinkage effect}

In Fig. 3 the unaccomplished humidity content was plotted as a function of time for the three drying temperatures $\left(60,70\right.$ and $\left.80^{\circ} \mathrm{C}\right)$. A linear function was obtained in all cases; hence the slope together with the mean logarithmic

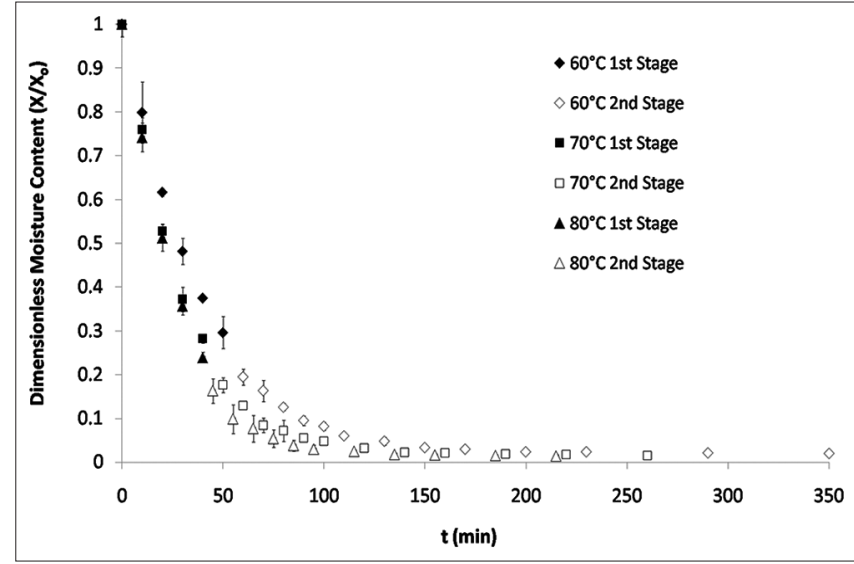

Fig 2. Drying curves of carrot cubes at different drying temperatures $\left(60,7080^{\circ} \mathrm{C}\right)$.

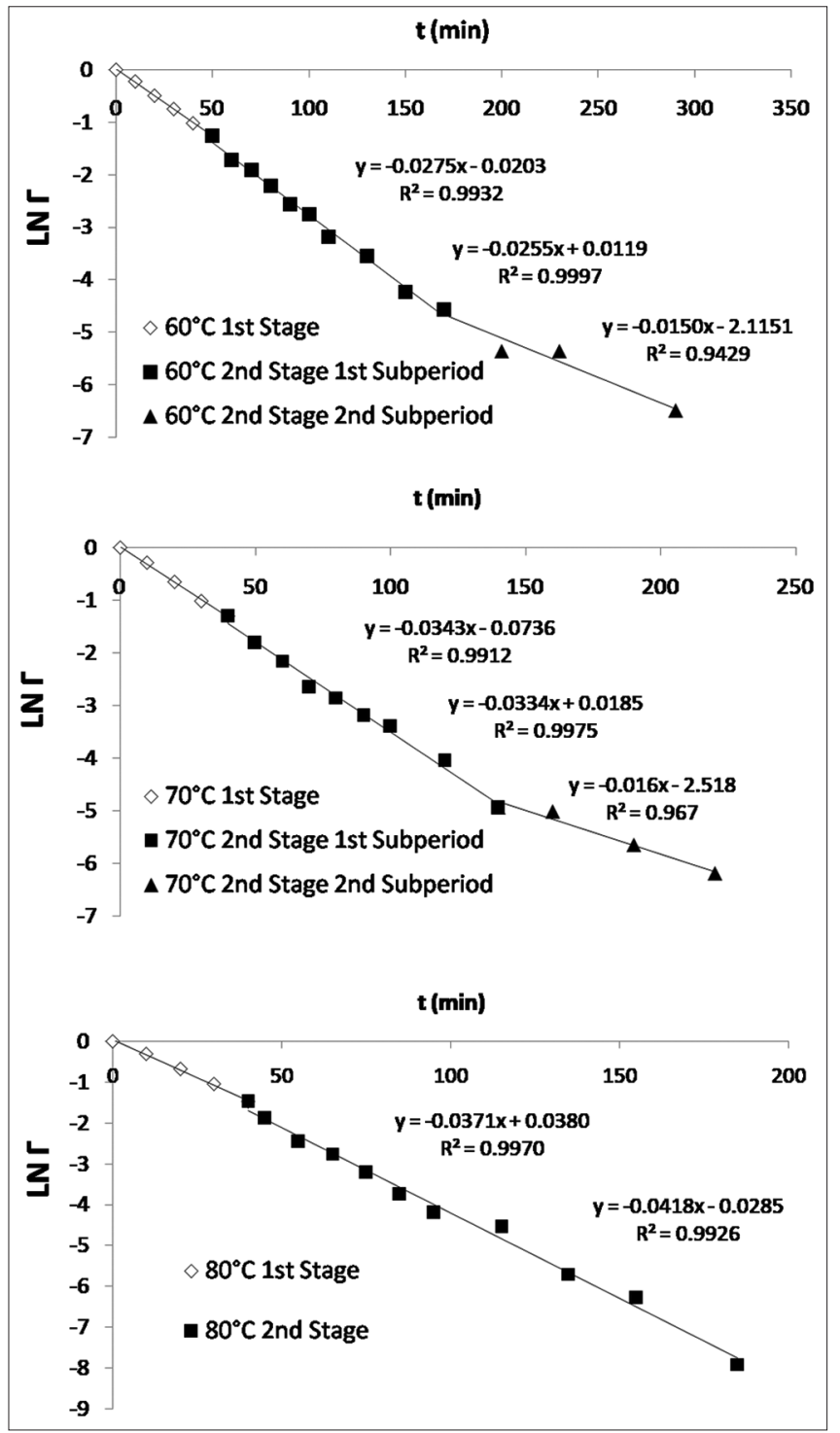

Fig 3. Unaccomplished moisture content vs time at different drying temperatures considering a LNR equivalent radius $\left(60,70,80^{\circ} \mathrm{C}\right)$ 
sphere equivalent radius was utilized in Fick's second law for a sphere, as shown in equation 3 , to evaluate the moisture effective diffusivity coefficient of carrot dices. When 60 and $70^{\circ} \mathrm{C}$ were used two subperiods in the second drying stage were observed so a moisture effective diffusivity coefficient was evaluated for each subperiod.

Table 1 briefs the numerical values of slopes calculated from Fig. 3 as well as moisture effective diffusivity coefficients without considering shrinkage effect for the three temperatures used in this work. From table 1, it is clearly seen that diffusivity increases with drying temperature indicating a faster mass transfer from the cubes to the drying air. The moisture effective diffusivity coefficients ranged from 1.228 to $1.639 \times 10^{-9} \mathrm{~m}^{2} / \mathrm{s}$ for the first drying stage in the conventional semipilot spouted bed dryer whereas for the second drying stage in the lab scale spout fluidized bed dryer with draft tube it ranged from 0.168 to $0.892 \times 10^{-9} \mathrm{~m}^{2} / \mathrm{s}$. This reduction in the effective moisture diffusivity coefficient might be related to a change in the diffusion mechanism due to considerable shrinkage during the second stage of drying. These results are comparable to the ones obtained by Cardenas-Bailon et al., (2017) where shrinkage was not considered.

\section{Effective moisture diffusivity coefficient calculation taking into account shrinkage phenomena}

Volume depletion of food products is a very ordinary physical effect observed during drying processes. Empirical mathematical models of volume depletion were calculated using linear regression analysis of shrinkage data. Variation in the dimensionless volume of dried carrot cubes $\left(\mathrm{V} / \mathrm{V}_{\mathrm{o}}\right)$ vs. dimensionless moisture content $\left(\mathrm{X} / \mathrm{X}_{\mathrm{o}}\right)$ during the two stage drying process are shown in Fig. 4. An ideal shrinkage was observed. The coefficients $\mathrm{A}$ and $\mathrm{B}$ for equation 4 were obtained from the linear equations resulting after plotting $\mathrm{V} / \mathrm{V}_{\mathrm{o}} \mathrm{vs} \mathrm{X} / \mathrm{X}_{\mathrm{o}}$ at every drying temperature. With this information and with the help of equation 5 it was possible to know the equivalent sphere radius $\left(r_{\text {eq }}\right)$ at any moisture content and at any drying time t.

In Fig. 5 the unaccomplished humidity content was plotted as a function of $\mathrm{t} / \mathrm{r}_{\mathrm{eq}}{ }^{2}$ for the three drying temperatures $(60$, 70 and $80^{\circ} \mathrm{C}$ ). A linear relationship was observed between the unaccomplished humidity content $\mathrm{vs} t / \mathrm{r}_{\mathrm{eq}}{ }^{2}$. In this case, only one subperiod in the second drying stage was observed unlike when shrinkage effect was not considered, where two subperiods were observed. From the slope of these equations the moisture effective diffusivity coefficient of carrot cubes taking into account shrinkage phenomena was evaluated.

The values of slopes obtained from Fig. 5 as well as moisture effective diffusivity coefficients taking into account shrinkage effect for the three temperatures used in this

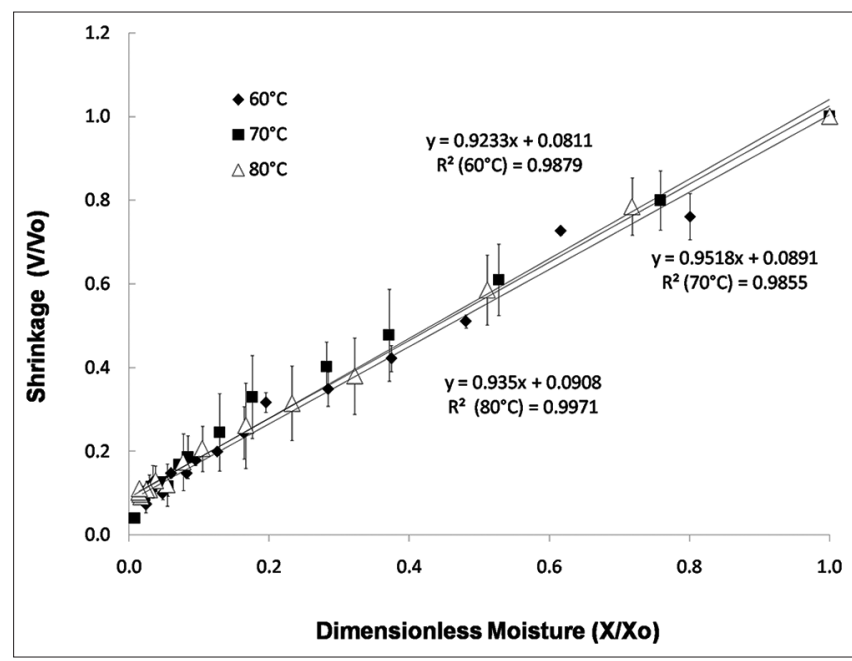

Fig 4. Shrinkage vs dimensionless moisture content for carrot cubes dehydrated in a two stage drying process at $60,70,80^{\circ} \mathrm{C}$.

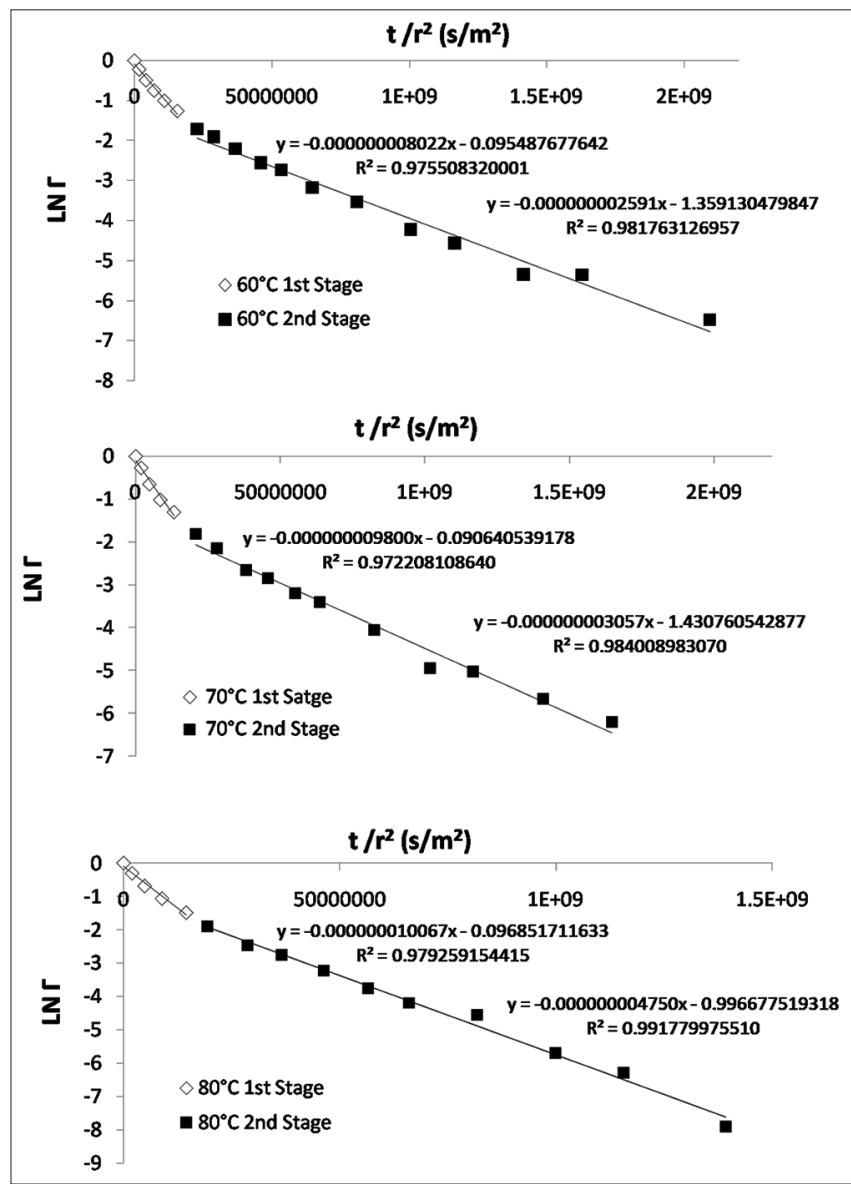

Fig 5. Unaccomplished moisture content $v s t / r_{e q}{ }^{2}$ for carrot cubes at different drying temperatures $\left(60,70,80^{\circ} \mathrm{C}\right)$.

work can also be seen in table 1 . In table 1 , it is shown how diffusivity increases with the drying temperature, indicating a faster mass transfer from the food into the drying air. The moisture effective diffusivity coefficients ranged from 0.821 to $1.02 \times 10^{-9} \mathrm{~m}^{2} / \mathrm{s}$ for the first drying stage in the conventional semipilot spouted bed dryer whereas for 
Table 1: Effective diffusion coefficients $\left(D_{\text {ef }}\right)$ in carrots cubes dehydrated in a two stage process without considering shrinkage effect and considering shrinkage effect

\begin{tabular}{|c|c|c|c|c|c|c|c|}
\hline \multirow[t]{2}{*}{ Drying temperature $\left({ }^{\circ} \mathrm{C}\right)$} & \multirow[t]{2}{*}{ Stage } & \multicolumn{3}{|c|}{ Without considering shrinkage } & \multicolumn{3}{|c|}{ Considering shrinkage phenomena } \\
\hline & & LNR (m) & Slope $\left(\mathrm{min}^{-1}\right)$ & $D_{e f} \times 10^{9}\left(\mathrm{~m}^{2} / \mathrm{s}\right)$ & Slope $\left(\mathrm{s} / \mathrm{m}^{2}\right)$ & $\alpha$ & $D_{\text {ef }} \times 10^{9}\left(\mathrm{~m}^{2} / \mathrm{s}\right)$ \\
\hline \multirow[t]{3}{*}{60} & 1 & 0.00516 & -0.0273 & $1.22 \pm 0.05$ & $-8.04 \mathrm{E}-09$ & $0.187 \pm 0.009$ & $0.821 \pm 0.02$ \\
\hline & 2 (S1) & 0.00352 & -0.0262 & $0.54 \pm 0.03$ & $-2.59 \mathrm{E}-09$ & $2.730 \pm 0.15$ & $0.262 \pm 0.01$ \\
\hline & 2 (S2) & 0.00278 & -0.0150 & $0.19 \pm 0.05$ & NA & NA & NA \\
\hline \multirow[t]{3}{*}{70} & 1 & 0.00511 & -0.0343 & $1.59 \pm 0.04$ & $-9.80 E-09$ & $0.170 \pm 0.04$ & $0.992 \pm 0.03$ \\
\hline & 2 (S1) & 0.00354 & -0.0334 & $0.70 \pm 0.03$ & $-3.05 E-09$ & $2.828 \pm 0.36$ & $0.309 \pm 0.01$ \\
\hline & 2 (S2) & 0.00250 & -0.0160 & $0.16 \pm 0.06$ & NA & NA & NA \\
\hline \multirow[t]{2}{*}{80} & 1 & 0.00512 & -0.0371 & $1.63 \pm 0.1$ & $-1.00 \mathrm{E}-08$ & $0.194 \pm 0.04$ & $1.020 \pm 0.2$ \\
\hline & 2 & 0.00356 & -0.0418 & $0.89 \pm 0.06$ & $-4.70 \mathrm{E}-09$ & $2.002 \pm 0.45$ & $0.481 \pm 0.03$ \\
\hline
\end{tabular}

$\mathrm{S} 1$ and $\mathrm{S} 2=$ subperiod 1 and 2 respectively; NA=Not applicable

the second drying stage in the lab scale spout fluidized bed dryer with draft tube, they ranged from $0.262 \times 10^{-9}$ to $0.481 \times 10^{-9} \mathrm{~m}^{2} / \mathrm{s}$. These values are lower than those obtained when shrinkage was not taken into account. These results can be interpreted as when shrinkage phenomena are considered, the equivalent radius is smaller thus the diffusion coefficients are lower than those obtained when shrinkage was not taken into account. These results are within the range of moisture effective diffusivity coefficients of carrot dried in a spout fluidized bed dryer reported by Zielinska and Markowsky, (2007) of around $0.458 \times 10^{-9}$ to $3.45 \times 10^{-9} \mathrm{~m}^{2} / \mathrm{s}$ taking into account shrinkage phenomena, but are dissimilar from those published by Markowsky et al., (2006) for not scalded carrot cubes dried in a fluidized bed dryer which ranged between $3.52 \times 10^{-9}$ and $6.92 \times 10^{-9}$ $\mathrm{m}^{2} / \mathrm{s}$ and those published by Doymaz (2004)for scalded carrot cubes in a cabinet dryer which varied from $0.776 \mathrm{x}$ $10^{-9}$ to $9.335 \times 10^{-9} \mathrm{~m}^{2} / \mathrm{s}$. The discrepancy might be due that the data by Markowsky et al., (2006) and Doymaz (2004) were calculated without considering shrinkage effect.

In addition, the term $6 / \pi^{2}$ (characteristic for a sphere) in the second Fick's law also needs to be corrected by the correction factor $\alpha$ calculated from the ordinate to the origin in the plot $\ln \Gamma \mathrm{vs} t / \mathrm{r}_{\mathrm{eq}}{ }^{2}$ as shown in equation 9. This correction is required since the term $6 / \pi^{2}$ in the answer to the second Fick's law is estimated taking into account the geometry as a perfect sphere and since the carrot cubes are not perfect spheres this correction needs to be considered in the empirical model.

Fig. 6 shows the empirical model built for the three temperatures $\left(60,70\right.$ and $\left.80^{\circ} \mathrm{C}\right)$ using Fick's second law according to equation 3 without considering the shrinkage effect, considering the shrinkage effect but without inserting correction factor $\alpha$, and considering the shrinkage effect as well as correction factor $\alpha$.

It can be seen how the empirical model without considering the shrinkage effect fails in predicting drying kinetics of carrot cubes dried in the two stage process using the conventional semipilot spouted fluid dryer and the lab scale spout fluidized bed dryer with draft tube at 60,70 and $80^{\circ} \mathrm{C}$. This failure is more drastic at high moisture content values for the three temperatures used in this work. The failure can be associated to considerable shrinkage of the particles thus an incorrect evaluation of effective moisture coefficient diffusivities.

Also, the empirical model built taking into account shrinkage phenomena but without inserting the correction factor $\alpha$ (Fig. 6) fails in predicting drying kinetics of carrot cubes dried in the two stage process. Prediction is even worse than when shrinkage effect was not considered. In this case the failure is attributed to the change of a regular geometry at the beginning of the drying into a totally irregular geometry at the final stage of the drying process due to shrinkage of the particles. For this reason Fick's second law designed for a perfect sphere fails in predicting drying kinetics of carrot cubes. It can be seen in Fig. 6 how the model underestimates drying kinetics in the first stage of drying and overestimates drying kinetics in the second stage of drying. This behavior is due to drastic change in slopes from stage 1 to stage 2 as shown in Fig. 5.

In order to consider the change of geometry during the drying process a correction factor $\alpha$ was included into the term $\mathbf{6} / \boldsymbol{\pi}^{2}$ (characteristic for a sphere). In Fig. 6 it can also be observed the model considering the shrinkage effect as well as correction factor $\alpha$ and how the empirical model succeeds in predicting drying kinetics at the three drying temperatures used at this work. The model predicts accurately drying kinetics of carrot cubes dried in the two stage process using the semipilot spout fluid dryer and the lab scale spout fluidized bed dryer. The correction coefficient $\alpha=0.187 \pm 0.009$ and $2.73 \pm 0.15$ at $60^{\circ} \mathrm{C} ; 0.170 \pm 0.04$ and $2.828 \pm 0.36$ at $70^{\circ} \mathrm{C}$ and $0.194 \pm 0.04$ and $2.002 \pm 0.45$ at $80^{\circ} \mathrm{C} \mathrm{C}$ for the first and second stage respectively is also an important parameter for the success of the model. This correction coefficient must be applied in the term $6 / \pi^{2}$ of the answer to the second Fick's law since carrot cubes are not perfect spheres. A clear relationship between the value 
of $\alpha$ and the drying temperature was not observed but this correction factor might be related to the variations in the geometry of the particles during the dehydration process.

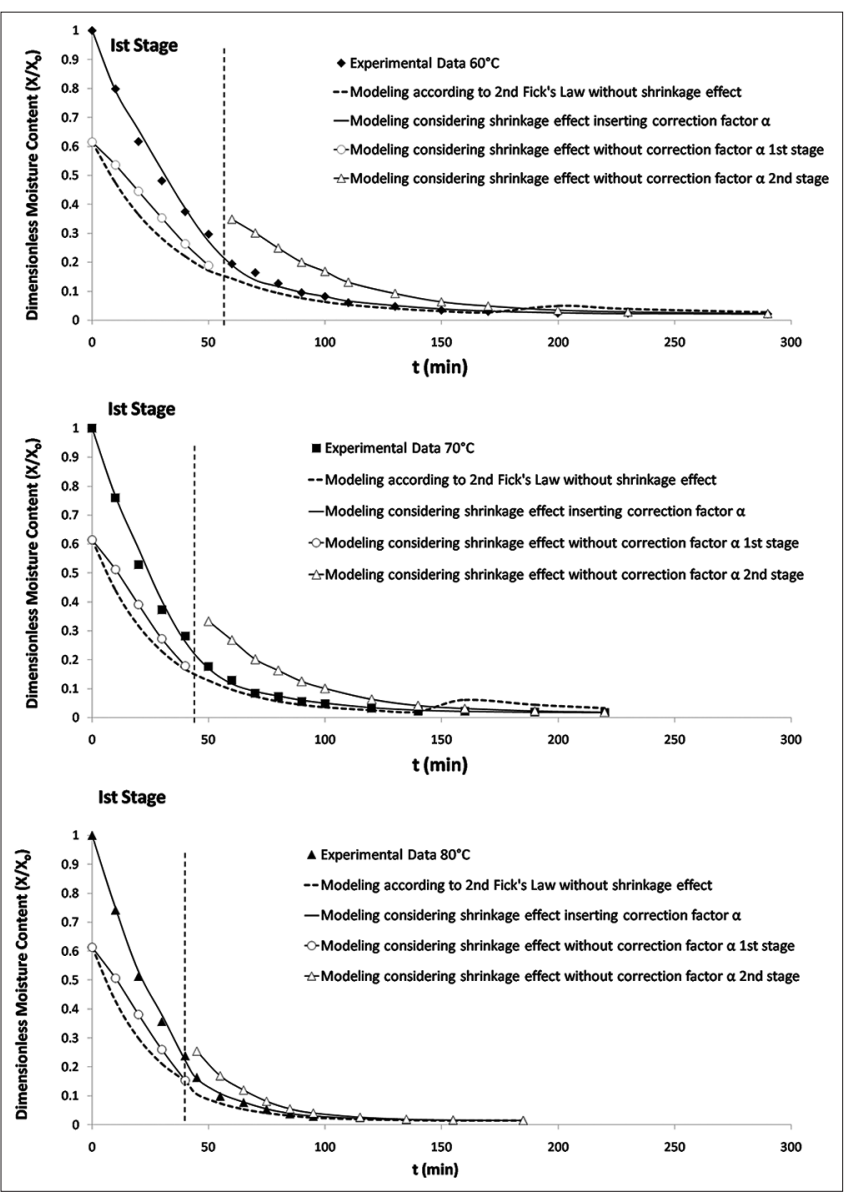

Fig 6. Drying kinetics prediction of carrot cubes without considering shrinkage, considering shrinkage without correction factor $\alpha$ and considering correction factor $\alpha=0.187 \pm 0.009$ and $2.73 \pm 0.15$ at $60^{\circ} \mathrm{C}$, $0.170 \pm 0.04$ and $2.828 \pm 0.36$ at $70^{\circ} \mathrm{C}$ and $0.194 \pm 0.04$ and $2.002 \pm 0.45$ at $80^{\circ} \mathrm{C}$ for the first and second stage respectively.
With respect to the accuracy of the models, it can be observed in table 2 how the SEEvalues ranged from 0.122 to 0.210 when shrinkage phenomena including correction factor $\alpha$ were considered, whereas when both, the $\alpha$ factor was not considered or the effect of shrinkage was neglected, SSE values ranged from 1.002 to 1.263 .

Fig. 7 shows the residuals plotted against the observed dimensionless moisture content $\left(\mathrm{X} / \mathrm{X}_{\mathrm{o}}\right)$ for the three mathematical models developed at $60^{\circ} \mathrm{C}$ : modeling according to $2^{\text {nd }}$ Fick's law but without considering shrinkage effect (Fig. 7a), modeling considering shrinkage effect but without inserting correction factor $\alpha$ (Fig. $7 \mathrm{~b}$ ) and modeling considering shrinkage effect inserting correction factor $\alpha$ (Fig. 7c). In Figure 7a it can be observed that residuals are in the range of -0.05 to 3.24 however it is clearly observed that variance of the model increased with the magnitude of the dimensionless moisture content, being the residuals positive in almost all the range, thus the model is inadequate to predict accurately the observed values underestimating them. The same situation was observed in Fig. $7 \mathrm{~b}$ when shrinkage effect was considered but correction factor $\alpha$ was not inserted. Residuals are in the range of 1.29 to 3.24 , a wider range than when shrinkage effect was not considered. In this case, it was observed that variance of the model increases with the magnitude of the dimensionless moisture content, being the residuals positive for the first stage and negative in the second stage, causing underestimated values in the first stage and overestimated values in the second stage. The model was inadequate to predict the experimental data. On the other hand, in figure $7 \mathrm{c}$, residuals are in the range of 0.34 to 0.20 closer to the $\mathrm{x}$ axis than in the other two cases. Also it is observed that residuals are randomly dispersed around the horizontal axis indicating that the model inserting the correction factor

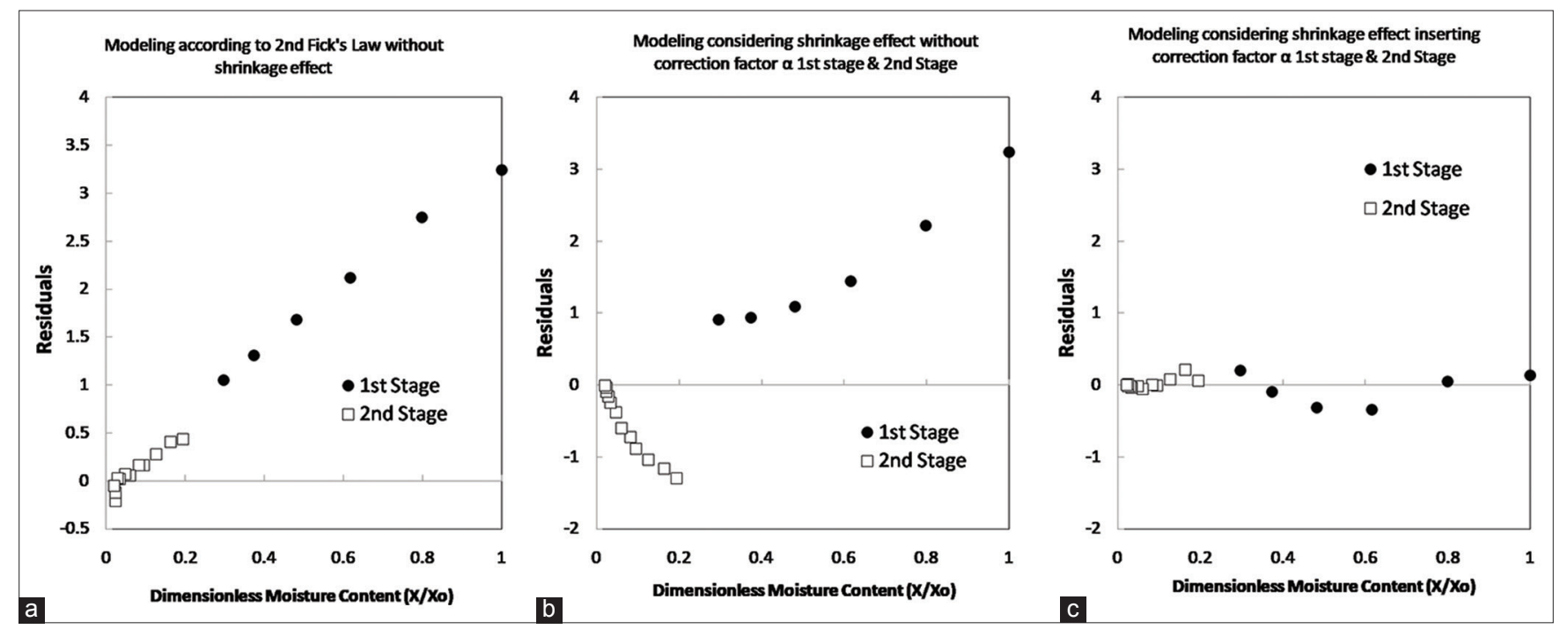

Fig 7. Residual analysis for the three models developed at $60^{\circ} \mathrm{C}$ vs dimesionless moisture content. 
Table 2: Statistics analysis to evaluate prediction accuracy and effectiveness of the models developed

\begin{tabular}{|c|c|c|c|c|c|c|}
\hline \multirow[t]{2}{*}{ Drying temperature $\left({ }^{\circ} \mathrm{C}\right)$} & \multicolumn{2}{|c|}{$\begin{array}{l}\text { Without considering } \\
\text { shrinkage effect }\end{array}$} & \multicolumn{2}{|c|}{$\begin{array}{l}\text { Considering Shrinkage but } \\
\text { without correction factor } \alpha\end{array}$} & \multicolumn{2}{|c|}{$\begin{array}{c}\text { Considering Shrinkage } \\
\text { including correction factor } \alpha\end{array}$} \\
\hline & MSE & SEE & MSE & SEE & MSE & SEE \\
\hline 60 & 1.597 & 1.263 & 1.469 & 1.212 & 0.018 & 0.134 \\
\hline 70 & 1.339 & 1.157 & 1.296 & 1.138 & 0.044 & 0.210 \\
\hline 80 & 1.287 & 1.134 & 1.005 & 1.002 & 0.015 & 0.122 \\
\hline
\end{tabular}

$\alpha$ is adequate to predict the observed values. Similar results were obtained for 70 and $80^{\circ} \mathrm{C}$ (Data not shown).

In conclusion, the model taking into account shrinkage effect and correction factor $\alpha$ describes much better drying kinetics of carrot cubes than the two other models developed.

\section{Quality assessment}

In Fig. 8 the percentage of $\beta$-carotene retention, POD residual activity and PME residual enzymatic activity for carrots dried in the two stage process can be seen. In every drying experiment the starting quality parameters besides the final quality parameters in the dehydrated cubes were tested to calculate the percent retention of each one, because the initial quality parameters resulted different from batch to batch significantly.

From Fig. 8, it can be observed that no statistical difference between the carotene content was found at any drying temperature. The retention of carotenes after the drying process was around $80 \pm 5.4 \%$ for all drying experiences. These results differ substantially from other reported results. Pan et al., (1997) found 41.9\% carotene retention in carrot cubes dehydrated in a vibrofluidized bed dryer at $100^{\circ} \mathrm{C}$ and Reyes et al., (2002) 30\% $\beta$-carotene retention in carrots dried in a fluidized bed dryer at $80^{\circ} \mathrm{C}$. On the contrary, the results obtained in this work are comparable to those reported by Lin et al., (1998), Zheng-Wei et al., (2004), Suvarnakuta et al., (2005), Castro et al., (2008), Goula and Adamopoulus, (2010), and Cardenas-Bailon et al., (2017) who reported a reduction of $19.2 \%, 30 \%$, $24 \%, 20 \%, 25 \%$, and $13 \%$ respectively during drying of carrots in cubes and slices in hot air or superheated steam, in different kind of driers.

PME is more thermoresistant than POD. This fact can be seen in Fig. 8 where at the three temperatures used in this work the PME residual activity is much higher than POD residual activity. The highest PME enzymatic residual activity $(95 \%)$ was obtained when $60^{\circ} \mathrm{C}$ was utilized and the lowest PME activity (85 and 83\%) was obtained when 70 and $80^{\circ} \mathrm{Cwere}$ used respectively. This outcome is in accordance to the one published by Cárdenas-Bailón et al., (2017) and they suggest that the higher the drying temperature, the more damage the product receives due to the thermal treatment, so this information should be considered when selecting the

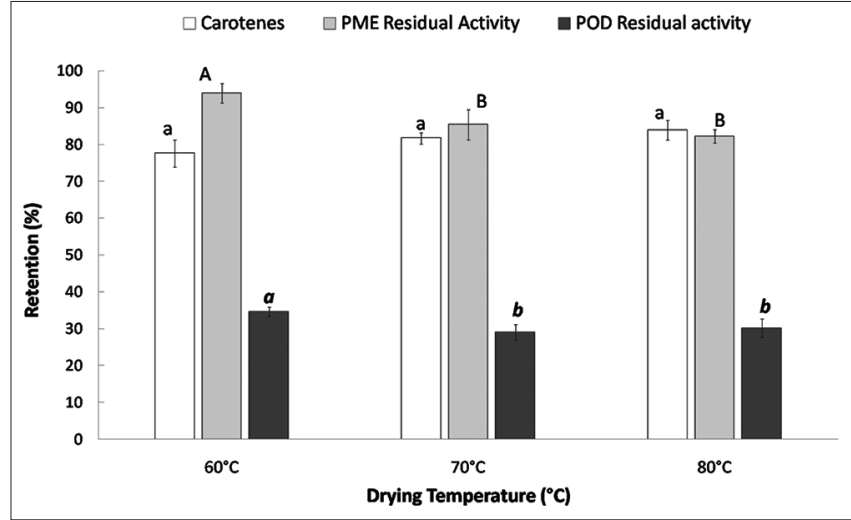

Fig 8. $\beta$-Carotene retention, PME and POD residual activity of carrot cubes dehydrated in a two stage process at $60,70,80^{\circ} \mathrm{C}$. Different letters mean there is significant statistical differences $p>0.01$.

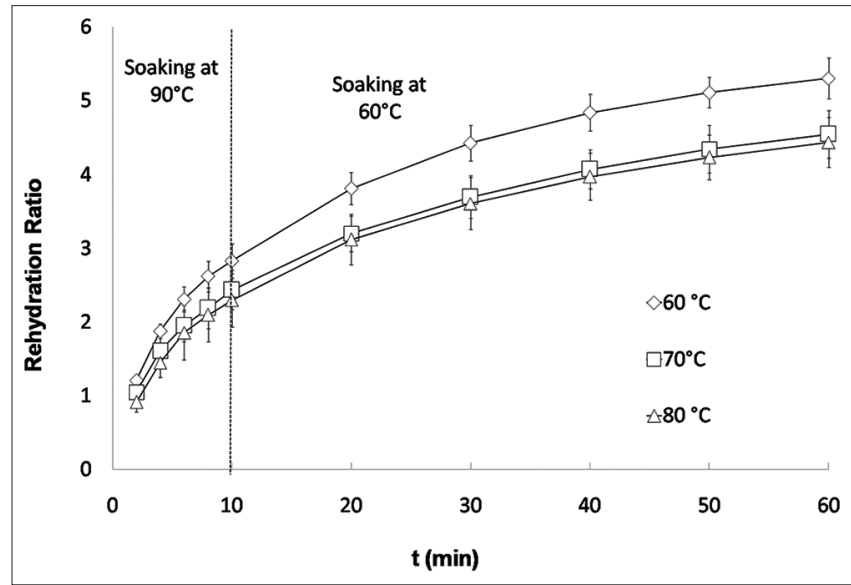

Fig 9. Rehydration ratio of carrot cubes dried at 60,70 and $80^{\circ} \mathrm{C}$ in a two stage drying process.

drying temperatures for drying carrot cubes, since higher temperatures may reduce the drying time but they also may have a bad impact on product quality.

Regarding peroxidase (POD) activity in dried carrots, Fig. 8 shows that the POD enzymatic residual activity varied from $30 \%$ to $35 \%$ depending on the drying temperature. The lowest POD enzymatic residual activity (30\%) was measured at $70^{\circ} \mathrm{C}$ or $80^{\circ} \mathrm{C}$ whereas the highest POD activity (around $35 \%$ ) was obtained at $60^{\circ} \mathrm{C}$. No statistical difference was found between the values obtained at 70 and $80^{\circ} \mathrm{C}$. This outcome is different from the one reported by Castro et al., (2008) who reported POD residual activity of up to $85 \%$ in carrot cubes dehydrated at $60^{\circ} \mathrm{C}$ in a 
vibrofluidized bed dryer but are closer to those reported by Cardenas-Bailon et al., (2017) who reported POD residual activity of around 40 to $66 \%$ for carrot cubes dehydrated in a spout fluidized bed dryer. From analysis of these results it can be concluded that at $60^{\circ} \mathrm{C}$ there is less thermal damage than at 70 or $80^{\circ} \mathrm{C}$ despite the longer drying times.

\section{Rehydration ratio}

The experimental data on rehydration ratio are presented in Fig. 9. The rehydration ratio of carrot cubes raised from 0 at the starting point of the experiment to around $5.3 \mathrm{~kg}$ of water absorbed $/ \mathrm{kg}$ dried solids at the end of rehydration process for carrots dried at $60^{\circ} \mathrm{C}$, and from 0 to $4.5 \mathrm{~kg}$ of water absorbed $/ \mathrm{kg}$ dried solids for carrots dried at $70^{\circ} \mathrm{C}$ and $80^{\circ} \mathrm{C}$. Likewise, it was noticed that the rehydration rate was higher during the first 2 min of rehydration process, which is in accordance with the outcome reported by Zielinska and Markowsky, (2007) and Lin et al., (1998). It can also be seen in Fig. 8 that during the two steps of rehydration process, both the humidity content and the rehydration ratio obtained for carrots dehydrated at $60^{\circ} \mathrm{C}$ were bigger than those for carrots dehydrated at 70 and $80^{\circ} \mathrm{C}$. These results suggest that drying at 70 and $80^{\circ} \mathrm{C}$ caused a broader damage of the cellular structure of the carrot dices resulting in a loss of rehydration capacity.

\section{CONCLUSIONS}

It was possible to dehydrate carrot cubes in a two stage process keeping the air velocity constant in each stage. The mathematical model developed in this work describes accurately the experimental data collected at different drying conditions. A linear relationship was detected between shrinkage ratio and humidity content; this relationship was used to solve the second Fick's law with one term of the series and a correction factor was included in the term $6 / \pi^{2}$ characteristic of sphere geometry. This correction factor might be related to the geometry of the cubes and how far it is from a sphere. It was confirmed that in order to estimate reliable effective moisture coefficients it is required to take into account shrinkage effect. Carotene retention was around $80 \%$ after the drying process regardless the temperature used. Drying at $60^{\circ} \mathrm{C}$ had less impact on residual PME and POD activities. Carrot cubes dehydrated at $60^{\circ} \mathrm{C}$ showed the highest rehydration ratio, compared to those dried at 70 or $80^{\circ} \mathrm{C}$ probably due to the more extensive damage at the microstructure caused at these higher temperatures.

\section{ACKNOWLEDGMENTS}

Financial support from Secretaria de Investigación y Posgrado Instituto Politécnico Nacional, Escuela
Nacional de Ciencias Biológicas Mexico and CONACYT Consejo Nacional de Ciencia y Tecnologia Mexico for the development of this work is greatly appreciated.

\section{Authors' contributions}

Perez-Vazquez Cinthia ran the experiments. CárdenasBailón Fernando wrote the manuscript and performed data analysis. Osorio-Revilla Guillermo was who developed experimental design, results interpretation and coordinated data analysis. Gallardo-Velázquez Tzayhri provided technical support of the experiments and performed statistical analysis.

\section{REFERENCES}

Anthon, E. G. and D. M. Barret. 2002. Kinetic parameters for the thermal inactivation of quality-related enzymes in carrots and potatoes. J. Agric. Food Chem. 50: 4119-4125.

Aprajeeta, J., R. Gopirajah and C. Anandharamakrishnan. 2015. Shrinkage and porosity effects on heat and mass transfer during potatodrying. J. Food Eng. 144: 119-128.

Arevalo-Pinedo, A., F. E. Xidieh-Murr, Z. D. Salles-Arevalo and A. D. Giraldo-Zuñiga. 2010. Modeling with shrinkage during the vacuum drying of carrot (Daucus carota). J. Food Process Preserv. 34: 611-621.

Aversa, M., S. Cursio, V. Calabro and G. Iorio. 2011. Measurement of the water-diffusion coefficient, apparent density changes and shrinkage during the drying of eggplant (Solanum melongena). Int. J. Food Prop. 14:523-527.

Białobrzewski, I., M. Zielinska, A. S. Mujumdar and M. Markowski. 2008. Heat and mass transfer during drying of a bedof shrinking particles simulation for carrot cubes driedin a spout-fluidizedbed drier. Int. J. Heat Mass Transf. 51: 4704-4716.

Brasiello, A., G. Adiletta, P. Russo, C. Silvestro, D. Albanese and M. Di Matteo. 2013. Mathematical modeling of eggplant drying: Shrinkage effect. J. Food Eng. 114: 99-105.

Brasiello, A., G. lannone, G. Adiletta, S. De Pasquale, P. Russo and M. Di Matteo. 2017. Mathematical model for dehydration and shrinkage: Prediction of eggplant's MRI spatial profiles. J. Food Eng. 203: 1-5.

Cárdenas-Bailón, F., G. Osorio-Revilla and T. Gallardo-Velázquez. 2017. Evaluation of quality parameters of dried carrot cubes in a spout-fluidized-bed dryer with and without draft tube. J. Food Meas. Charact. 11: 245-255.

Castro, F. P., M. T. Cruz y Victoria, A. I. Sosa, V. M. Mendoza and S. T. Pineda. 2008. Biochemical quality assessment of dehydrated carrots. Int. J. Food Prop. 11: 13-23.

Crank, J. 1975. The Mathematics of Diffusion. $2^{\text {nd }}$ ed. Oxford University Press, Oxford.

Doymaz, I. 2004. Convective air drying characteristics and selected quality attributes of dried carrots. J. Food Eng. 61: 359-364.

Goula, A. M. and K. G. Adamoupoulus. 2010. Kinetic models of $\beta$-carotene degradation during air drying of carrots. Drying Tech. 28: 752-761.

Hassini, L., S. Azzouuz, R. Peczalski and A. Belghith. 2007. Estimation of potato moisture diffusivity from convective drying kinetics with correction for shrinkage. J. Food Eng. 79: 47-56.

Hatamipour, M. S. and D. Mowla. 2002. Shrinkage of carrots during drying in an inert medium fluidized bed. J. Food Eng. 55: 247-252. 
Krokida, M. K. and Z. B. Maroulis. 1997. Effect of drying method on shrinkage and porosity. Drying Tech. 15(10): 2441-2458.

Lin, T. M., T. D. Durance and C. H. Scaman. 1998. Characterization of vacuum microwave, air and freeze dried carrot slices. Food Res. Int. 31(2): 111-117.

Markowski, M., I. Stankiewicz, P. Zapotoczny and J. Borowska. 2006. Effect of variety on drying characteristics and selected quality attributes of dried carrots. Drying Tech. 24: 1011-1018.

McLaughlin, M. C. and T. R. A. Magee. 1998. The effect of shrinkage during drying of potato spheres and the effect of drying temperature on Vitamin C retention. Trans. Inst. Chem. Eng. 76: 138-142.

Mc Minn, W. A. M. and T. R. A. Magee. 1997. Physical characteristics of dehydrated potatoes-Part I. J. Food Eng. 33: 37-48.

Montgomery, D. C. 2002. Applied Statistics and Probability for Engineers. $3^{\text {rd }}$ ed. John Wiley and Sons, USA.

Morales-Blancas, E. F., V. E. Chandia and I. Cisneros-Zevallos. 2002. Thermal inactivation kinetics of peroxidase and lipoxygenase from broccoli, green Asparagus and carrots. J. Food Sci. 67(1): 146-154.

Mulet, A. 1994. Drying modeling and water diffusivity in carrots and potatoes. J. Food Eng. 22: 329-348.

Nguyen, B. L., A. M. Van Loey, D. Fachin, I. Verlent and M. E. Hendrickx. 2002. Partial purification, characterization, and thermal and high-pressure inactivation of pectin methylesterase from carrots (Daucus carota L.). J. Agric. Food Chem. 50: 5437-5444.

Pan, Y. K., H. Wu, Z. Y. Li, A. S. Mujumdar and T. Kudra. 1997. Effect of a tempering period on drying of carrot in a vibro-fluidized bed. Drying Tech. 15(6): 2037-2043.

Reyes, A., P. I. Alvarez and F. H. Marquardt. 2002. Drying of carrots in a fluidized bed. I. Effects of drying conditions and modeling. Drying Tech. 20(7): 1463-1483.

Sjölmon, I. and V. Gekas. 1995. Apple shrinkage upon drying. J. Food Eng. 25: 123-130.

Stoforos, N. G., S. Crelier, M. C. Robert and P. S. Taoukis. 2002. Kinetics of tomato pectin methylesterase inactivation by temperature and high pressure. J. Food Sci. 67(3): 1026-1031.

Suvarnakuta, P., S. Devahastin and A. Mujumdar. 2005. Drying kinetics and $\beta$-carotene degradation in carrot undergoing different drying process. J. Food Sci. 70: 520-526.

Zheng-Wei, C., X. Shi-Ying and S. Da-Wen. 2004.Effect of microwavevacuum drying on the carotenoids retention of carrot slices and chlorophyll retention of Chinese chive leaves. Drying Tech. 22(3): 563-575.

Zielinska, M. and M. Markowsky. 2007. Drying behavior of carrots dried in a spout fluidized bed dryer. Drying Tech. 25(1): 261-270.

Zielinska, M. and M. Markowsky. 2010. Air drying characteristics and moisture diffusivity of carrots. Chem. Eng. Process. 49: 212-218. 